$$
\operatorname{couf} 940630-56
$$

UCRL-JC-117467

PREPRINT

\title{
National Ignition Facility Environmental Protection Systems
}

J. Mark Mintz

Thomas C. Reitz

Michael T. Tobin

This paper was prepared for sibmittal to the Eleventh Topical Meeting on the Technology of Fusion Energy

New Orleans, Louisiana

June 19-23, 1994

June 1994

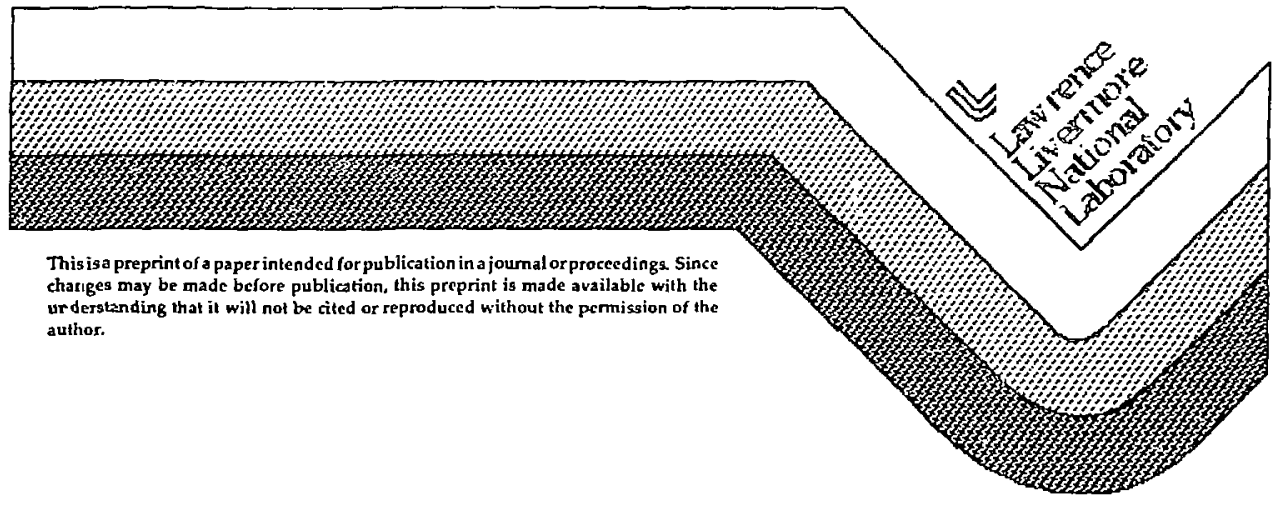




\section{DISCLAIMER}

This document was prepared as an account of work sponsored by an agency of the Uniled States Government. Neither the Unuted States Govermment nor the University of Califomia nor any of their employees, makes any wartanty, express or implied, or assumes any legal tiability or responsibility for the accuracy, completeness, or usefulness of any information, apperarus. produch, or process disclosed, or represents that its use would not infringe ptivately owned rights. Reference hetein to any specific commercial products, process, or service by trade name, trademark, manufacturer, or otherwise, does not nesessarily constinte or imply its endorsement, recommendation, or favoring by the United States Government or the University of Califomia. The views and upinions of authors expressed herein do not neiessarily state or refleet those of the United States Government or the University of Califomia. and shall not be used for advertising or product endorsement purposes. 


\section{NATIONAL IGNITION FACILITY ENVIRONMENTAL PROTECTION SYSTEMS}

\author{
J. Mark Mintz \\ Lawrence Livermorr National Lab \\ P.O. Box 808 \\ Livermore, Calif. 94550 \\ (510) $422-8394$
}

\author{
Thomas C. Reitz \\ Lawrence Livermore National Lab \\ P.O. BOx 808 \\ Livermore, Calif, 94550 \\ (510) $422-9: 23$
}

\author{
Michael T. Tnbin \\ Lawrence Livermore National Lab \\ P.O. BOX 808 \\ Livermore. Calir. 94550 \\ (510) 423-1168
}

\section{ABSTRACT}

The conceptual design of Environmental Protection Systems (EPS) for the National Ignition Facility (TIF) is described. These systems encompass tritum and activated debris handling, chamber, debris shield and general decontamination, neutron and gamma monitoring, and radioactive, hazardous and mixed waste handling. Key performance specifications met by EPS designs include limiting the tritium inventory to $300 \mathrm{Ci}$ and total tritum release from NIF facilities to less than $10 \mathrm{Ci} / \mathrm{yr}$. Total radiation doses attributable to $\mathrm{NIF}$ shall remain below $10 \mathrm{mrem} / \mathrm{yr}$ for any member of the general putlic and $500 \mathrm{mrem} / \mathrm{yr}$ for NIF stafl LARA-based design features and operational procedures will, in most cases, result in much lower measured exposures. Waste minimization, in proved cycie time and reduced exposures all result from the proposed $\mathrm{CO} 2$ robotic arm cleaning and decontamination system, while effective iritum control is achieved through a modem system design based on double containment and the proven detritiation lechnology.

\section{INTRODUCTION}

The National Ignitior Facility is designed to achieve signiticant D-T fusion yield, up to $20 \mathrm{MJ} /$ shot. In addition to unburned tritium, this process will generate neutrons, energetic particles and debris and $x$ rays. The neutrons will, in tum, mildly activate surrounding materials, including equipment, shielding, support structures and air gases. NIF Environmental Protection Systems have been designed to effectively minimize personnel exposures and adverse envisonmental effects. EPS elements are identified in Figure 1. Intrinsic NIF operational characteristics, coupled with conservative design principles, assure EPS designs that meet, or, guidel by ALARA, frequenty exceed all statutory and regu, atory requirements. The selected designs depend on a 'ariety of tritium processing systems, decontamination techniques and contamination control procedures.

Gas phase tritium from the larget chamber or other sealed enclosures, such as glove boxes, will be processed through a central tritium scrubber system. The scrubber system design will be based on the well established rechnique of catalytic oxidation with the resultant HTO collected on molecular sieve dryers. The scrubber system will be sized to accommodate multiple sources of tritiated effluent simultaneously. Given the projected design of the larget chamber vacuum system and operating parameters of the target chamber ilself, the tritium scrubber system need not be sized to process gas at a rate equal to the pumping speed of the vacuum system. A moderazely sized tritium processing system of approximately 2000 liters per minute should therefore meet NIF requirements. A larger capacity might prove necessary if chamber structures trap tritum more effectively than anticipated.

A relatively new process, $\mathrm{CO}_{2}$ pellet cleaning, is being evaluated as the primary decontamination process for all tritiated NF components. Winile some development work will be required to quantify the effectiveness on the various surfaces involved, a study completed by Martin Marielta indicates the process is applicable to this task. The technique could be applied to cleaning operations on both the interior and exterior of the target chamber and the associated debris shields. Assuming the initial optimisrs for $\mathrm{CO}_{2}$ pellel cleaning of tritiated NIF components is validated by testing, a significant saving in labor, reduced cleaning cycle times and waste generation will be realized. To 
urifornly clean and access the interior of the tanget chamber, the nozzle of the $\mathrm{CO} 2$ cleaning equipment could be controlled by a robotic arm that would be inserted into the chamber during cleaning operations. P. close capture collection shroud attached to the nozzle would collect and route the contaminates out of the chamber and away from the cleaned surfaces, this minimizing recontamination during the cleaning process.

Off line work areas will be developed for secondary cleaning, decontamination, and waste processing operations. $\mathrm{CO}_{2}$ pellet cleaning could also be applied to these off line operations with similar expectations for reduced labcr costs and waste generation.

To provide information on the effectiveness of the tritium processing equipment contamination control procedures, and to monitor tritium process releases, a comprehensive system of uritum monitors will be installed. In line tritum process monitors will evaluate scrubber performance, while work areas in glove boxes, ventilated hoods, and labs will be continually monitored for tritium levels. Stack monitors will evaluate both real time and accumulative stack releases. Liquid scinlillation counters will be used to evaluate surface contamination levels.

Exposure to neutron gamma and $\mathbf{x}$-radiation is minimized in NIF primarily by fixed shielding. access, and ventilation control. Target chamber debris will also be mildly aclivalcd, a faclor which influences waste handling glove box design and procedures. All non-mixed radioaclive waite is expected to qualify as low level waste and will be packaged and certified per criteria established by DOE/ NV for disposal at the Nevada Test Site. Mixed waste generaidon is expected to be minimal due to extensive lise of the $\mathrm{CO}_{2}$ pellet cleaning process.

\section{EPS ELEMENTS}

\section{A. Tritium Processing System (TPS)}

Tricium will be present in the NIF target chamber, diagnostic lines of sight, vacuum systems and glove boxes. It's removal by the TPS will be accomplished by the catalytic conversion of tritium to tritiated water to be stored on dryer beds for disposal at a later date. Based on Tritium Inventory Removal Project experience for the LLNL tritiun facility, the decontamination factor for the TPS should be approximately 10,000 of better. A flow schematic for the TPS os govem as Figure 2.

The TPS is composed of hardware which is mounted on a $10^{\prime}$ by $10^{\prime}$ by 7 ' high skid and monitoring and control systems located elsewhere.
The monitoring and control systems will be composed of the following:

- The flow monitoring system provides verification of gas now.

- The pressure monitoring system provides for system pressure monitoring.

- The temperature monitoring system provides for process temperature monitoring.

- The preheaterfreactor control system provides for reactor temperature control and over temperature protection.

- The hygrometer system provides for the monitoring of moisture breakthrough in the dryer beds.

- The tritium monitor system provides the means for monitoring tritium contamination levels of the gas entering and leaving the TPS.

- The process control system provides the control for the gas flow with the pneumatic valves.

The Tritiun Processing System will have to interface with any system or work station which could or will be exposed to tritrum. The main interfaces are the vacuum pumping systems for the target chamber and diagnostic lines of sight, the decontaminalion work stations and the target receiving and storage station. These systems, to the extent practical, will be co-located near the uarget chamber. Colocation will help assure contamination control (physical and HVAC pressure zone maintenance) and minimize the total EPS "footprint" and associated costs.

\section{B. Debris Shield Decontamination}

Debris shiclds protect sensitive NIF epties from blast damage. The clcaning/decontamination of the debris shields may be performed in one of two different ways-in situ, as part of the Target Chamber-Interior Decontamination or offline within the confincs of a dedicated Debris Shield Decontamination Station. At this time, the determining factor is choosing the appropriase cleaning method is whether or not the debris shield optical surfaces ane coated and if so, are they coated with a material that would be damaged/removed by the $\mathrm{CO}_{2}$ cleaning process? Assuming that the surface coating would be damaged by the cleaning process, the following procedure would be implemented.

The NIF Debris Shields (DS), configured in "cassettes," will be transferred directly from the NIF chamber into secondary containers, jointly removed and transferred to an off-line cleaning station. This process will be conducted using the philosophy of "total hermetic sealing" throughout the entire transfer sequence, i.e. from NIF chamber to transfer container to cleaning station. This methodology is designeded to protect personnel and tha eлvironment from exposure to tritium-contaminated surfaces and external radiation 
produced by activation. Upon insertion into the cleaning station, the DS/cassette assemblies are staged within an on-board sequencer and then individually cleaned to specification.

The proposed automated cleaning process concept involves techniques utilizing commercially-available, "pelistized $\mathrm{CO}_{2}$ blasting" equipment for surfacecontaminant removal. This concept (pending tritum rinoval-affectiveness experimentation/verification) will be utuized for DS cleaning. The process will involve simultaneous face-surface cleaning achicved by rototically-controlled single-axis (fore and aft) ranslation ard indexing (up and down) of the DS/ cassetie assembly through the pelletized $\mathrm{CO}_{2}$ media delivered by two opposed "nozzles"_-each biased to achieve an injpingement angle of $30-45$ degrees to the respective DS surface. The subsequent air-born contaminants liberated from this process will be collected locally (approximately $90 \%$ ) by two coneshaped close-canture accumulator housings (surrounding each nozzr) and connected, via flexible ducting. to a HEPA-filtered-sub-atmospheric Debris Recovery System capable of an evacuation flow rate of approximately 6000 SCFM.

\section{Tanget Chamber-Interior Decontamination}

Assuming acceptable tritum removal/first-wall material compatibility, the interior of the NIF chamber will be cleaned and decontaminated remotely utilizing similar conceptual techniques, media and equipment outlined in Debris Shield Decontamination, i.e. "pelletized $\mathrm{CO}_{2}$ blasting". The vehicle for delivering the cleaning media to the desired surfaces/locations will be an insertable (into NIF chamber) robotic ant with 6 degrees of freedom of movement and a minimum payload capacity of 150 pounds at th: articulated "wrist". The robotic arm will be conirolled by a computer-based controller with the ability to "lear" from the use of a model or 3-D CADD drawing to follow the required geometric paths for cleaning the complex internal surfaces. The use of the robolic system for cleaning minimizes the need for personnel entry into the NIF chamber and therefore reduces "risk" due to potential radioactive or questionable breathing-air environments. The robot is also capable of handling the massive cleaning nozzle/close-capture recovery system shroud assembly and the thrust generated by the $\mathrm{CO}_{2}$ delivery nozzle while positioning it at desirable impingement angles thus providing consistent translational paths to achieve optimum cleaning characteristics.

The $\mathrm{CO}_{2}$ cleaning media will be delivered, at the rate of about 200 pounds/hour, by dry compressed-air propulsion. The subsequent air-bome contaminants liberated from this cleaning process will be collected at the point of generation (approximately $90 \%$ ) by a coneshaped accumulator housing (surrounding the nozzle) and connected, via flexible ducting, to a HEPAfiltered-sub-almospheric Vacuum Debris Recovery System capable of an evacuation flow rate of approximately 6000 SCFM. A Make-Up Air System, pressure controlled by the Make-Up air Pressure Control System, will provide moisture/oil free air to replace that which is being swept through the Debris Recovery system and exhausted [after being monitcred by an inline tritium monitor] to the atmosphere through the facility "stack".

\section{General Decontamination Work Station}

The purpose of the General Decontamination Work Station (GDWS) is to provide an oft-line cleaning/decontamination capability for NIF-related components. The GDWS is comprised of a twelvefoot long ( $540 \mathrm{ft}^{3}$ ) glove box enclosure located within the confines of the Environmental Protection Systems (EPS) Processing Facility. This enclosure will be equipped wilh $\mathrm{CO}_{2}$ cleaning capabilities (both pelletized and liquid-generated "snow"), a close-capture vacuum recovery system, and a pressure-controlledmake-up-air conditioning system. Due to the large mass of the $\mathrm{CO}_{2}$ nozzlefrecovery system shroud and the thrust produced by delivery of the cleaning media, the $\mathrm{CO}_{2}$ cleaning head assembly will be remctely positioned by a joy stick-controlled robotic am mounted within the glove box. Assorted positioning equipment such as a lift platform, rotating/tilting mecharism, etc. with also be installed to facilitate cleaning operations of a variety of shapes/configurations. Like the Debris Shield Deconlamination Staion, the aggregate of gases yielded from the GDWS will be exhausted to the atmosphere through the facility "stack" after being riltered by the HEPA-filtered-subatmospheric Debris Recovery Sysiem (shared with the Debris Shield Decontamination Station) and monitored by a dedicated tritum monitor.

\section{E. Gamma and Neutron Moniloring}

The gamma and neutron monitoring systems for NIF are designed to continuously measure radiation at their respective locations. These monitors will provide local readout and alarm, as necessary. These readings will be provided to the NIF control system and other locations as required. The central NIF computer system will be able to interrogate the system from the control room and at the entrances to the target area to 
determine function statis and readout. The gamma measurement system provides an interlock signal to the target area and experimental doors to control entry, as required. The detectors will monilor radiation on a shot per shot basis. The neutron deloctors are designed to nos become activated frün neutrons produced during each shot. All electronics associated with the monitoring system and which are located within the target area are designed to continue operation in all cases of neutron exposure and not be adversely affocted by extra cameral effects. The monitors are designed to fail to the top of their measurement range. In no case will these monitors fail to the low end of their measurement range. The delectors are responsive to radiation over their entire range and their response is linear (within \pm 20 percent). The monitor channels (i.e. the detector, cabling, electronics) are designed to be calibrated as a unit.

The garmma and ncutron monitoring system will be located within the target room and other appropriate areas. in addition to the fixed locations shown in the rigurc, there will be four porable units for each type of radiation which can be placed in specific experimental areas to provide for comprehensive evaluations of local conditions. The monitoring systems are state of the art and are available from several vendors. Neutron detectors will be ${ }^{3} \mathrm{He}$ hased, while gamma and beta detectors will be ion chambers. The gamma and neutron monitoring systems are interfaced with the N[F computer control systcin and to the target room and experiment room door locks. Interlocks are designed to fail closed.

\section{F. Radioactive, Hazardous and Mixed Wastc} Sircams

Routine NIF operations will gencrate a variety of waste streams, including low level radioactive waste (LLRW), hazardous waste and small amounts of mixed waste. This section briefly describes these waste streans and how they are to be managed.

Table I summarizes principal constituents and their estimated generation rates. Much of this dala is extrapolaled directly from NOVA experience. Mixed waste quantities for NIF are, however, mich reduced by substituting the $\mathrm{CO}_{2}$ pellet clcaning process described in Il. B for the solvenis used in NOVA for the chamber and debris shield cleaning. Waste stream reductions of up to 100 percent for liquid mixed waste and 50 percent for solid mixed waste are anticipated and are reflected in Table 1.

LLRW will be generated principally by tritum systems operations and by periodic cleaning of first wall debris shield and diagnostics accessing the target cham- ber. Protective clothing (gloves, lab caats, etc.) will make up the bulk of this waste smeam with molecular sicves from the tritum processing system accounting for virtually all waste tritium inventory $(-300 \mathrm{Ci} / \mathrm{yr})$. LLRW will be characterized, packagcd and shipped in accordance with existing LLNL proccdures accepted for the disposal of tritiated wasce at the Nevada Test Site.

Small amounts of parciculate, which might include some mixed waste, will be dislodged during the cleaning operations described in Section II.C. These will be collected on HEPA filters and stored on site until determined not to be mixed or until a suitable processing site is available.

Liquid hazardous waste (in the forms aid approximate amounts listed in Table I) will be generated by various NIF operations, including optics cleaning (organic solvents) and photographic processing. These activities are routine at many large research facilities and the resulting incremental waste streams should be readily absorbed by the host site's exisling waste management process.

Solid hazardous waste will consist primarily of sealed oil-filled capacitors with a smaller component of solvent exposed wipes and protective clothing. As for liquid hazardous wastc, these items present no unusual disposal difficulties and can be readily absorbed by a host site's existing waste management infrastructure.

The assumed efficacy of the $\mathrm{CO}_{2}$ pellet cleaning process is the key to minimizing mixed waste generation in NEF.

\section{G. Tritum Monitoring \& Contamination Control}

1. Tritum Monitoring - A comprehensive system of process and work space tritium monitors will be utilized for all tritium operations associated with NIF. This monitoring scheme provides for continual monitoring of tritium operations from the location of the operation to the elcvated release point. The approach selected is consistent with modem tritium facility design philosophy and will provide complete local and remote information on tritum concentrations within NIF systems and work spaces.

Gas phase tritium will be primarily monitored through the use of ion chamber based detectors. Tritium monitoring will be provided at the following locations:

- Central triujum processing system.

- Target chamber interior.

- Glove box enclosures.

- Ventilated hoods. 
Figure 1: NIF EPS Elements

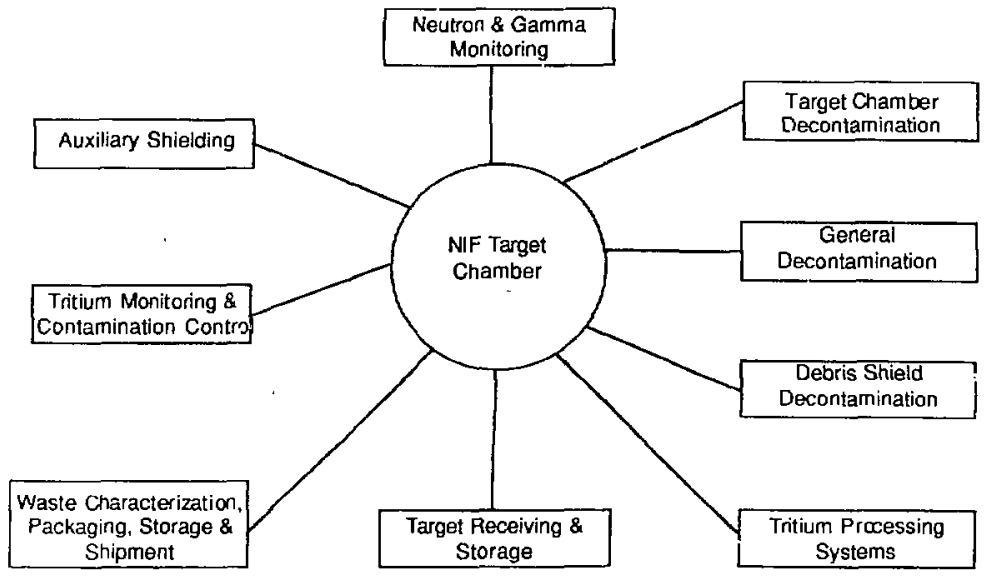

Figure 2: NIF Tritium Processing System

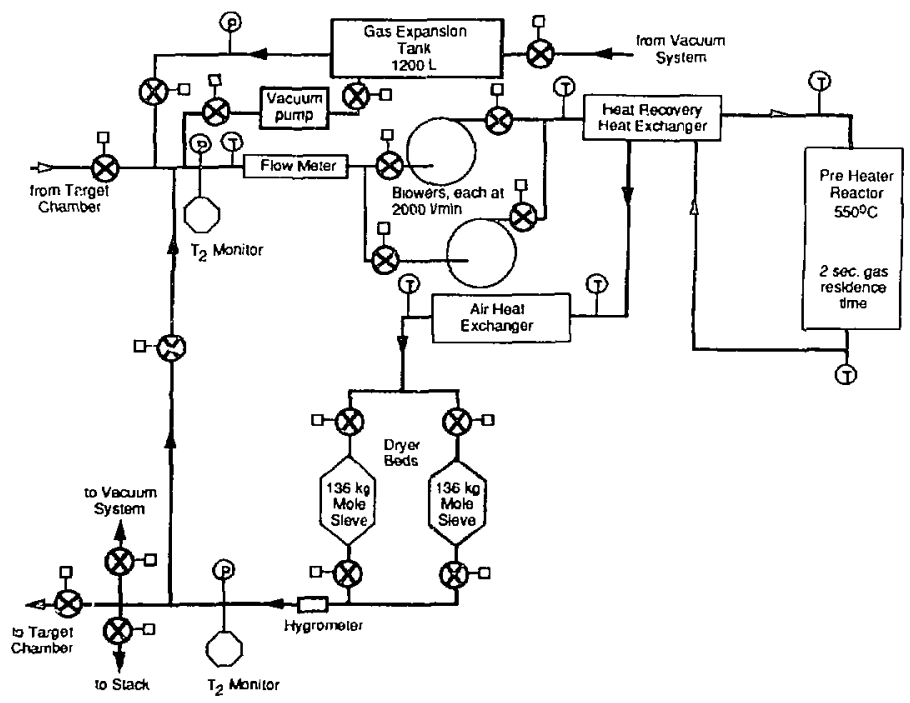


- Rooms involving tritium operations.

- Central exhaust stack.

- Diagnostic lines.

Local output of all tritium monitors will be provided.

A central control console will be provided in which the output of all monitors can be displayed and recorded. Provisions for alarms and interlocks will also be provided. In addition to the above permanent monitors, portable monitors will be utilized during localized maintenance type tritium operations.

To provide an accurate record of total tritium releases from NIF to the environment, an accumulative stack monitor will be provided. The instrument will be based on the Ostlund HTO/HT sampling technique and will monicor and record all stack effluent.

2. Contamination Control - As part of the overall facility radiological protection program, a detailed tritiun contamination control plan will be developed that will address operational procedures, personnel training, and contamination control evaluation. Written operating procedures aimed at minimizing contamination at the source will be provided. These procedures, which will be specific tc NIF operations, will be used to train individuals working in tritiated areas and will be a portion of an overalt Healih Physics program. To cvaluate the effoctiveness of the contamination control program, a liquid scintillation counting facility will be provided. The seintillation counter will be used to evaluate surface contamination levels through a rutine surface wipe program. A bioassay program will be implemented to evaluate the effectiveness of the contamination conirol plan in relation to personnel exposures.

\section{ACKNOWLEDGMENTS}

This work was performed under the auspices of the U.S. Department of Energy by Lawrence Livermore National Laboratory under Contract W-7405-Eng-48. The substantial technical contributions of NIF/EPS team members, Frank Drobnik and Paul Smuda, both of LLNL, are gratefully acknowledged.

Table I

Waste Generation Rates Projected for NIF

\begin{tabular}{|c|c|c|c|}
\hline \multirow[b]{2}{*}{ Wasle Type } & \multicolumn{2}{|c|}{ Quantity } & \multirow[b]{2}{*}{ Source } \\
\hline & withoul $\mathrm{CO}_{2}$ sys & with $\mathrm{CO}_{2}$ sys & \\
\hline Solid hazardous & $7,000 \mathrm{lb} / \mathrm{y}$ & $7,000 \mathrm{lb} / \mathrm{y}$ & capacitors, solvents on wipes and gloves \\
\hline Liquid hazardous & $500 \mathrm{gal} / \mathrm{y}$ & $500 \mathrm{gal} / \mathrm{y}$ & paints, acids, bases, alcohols, organic solvents, and photodevelope \\
\hline \multirow[t]{2}{*}{ Solid mixed } & $600 \mathrm{lb} / \mathrm{y}$ & & solvents on wipes, gloves, and clothing exposed to low Ievel H3 \\
\hline & & $300 \mathbf{l b} / \mathbf{y}$ & $\mathrm{CO}_{2}$ cleaning system filters * \\
\hline \multirow[t]{2}{*}{ Liquid mixed } & $1,000 \mathrm{gal} / \mathrm{y}$ & & $\begin{array}{l}\text { rinse water with solvents and low level } \mathrm{H}_{3} \text {; and contaminaled } \\
\text { organics }\end{array}$ \\
\hline & & $500 \mathrm{gal} / \mathrm{y} *$ & $\begin{array}{l}\text { rinse water with solvents and low level } \mathrm{H}_{3} \text { from components not } \\
\text { efficiently cleanable by } \mathrm{CO}_{2} \text { : and contaminated organics }\end{array}$ \\
\hline $\begin{array}{l}\text { Solid low level } \\
\text { radioactive }\end{array}$ & $2,000 \mathrm{lb} / \mathrm{y}$ & $2,000 \mathrm{lb} / \mathrm{y}$ & $\begin{array}{l}\text { gloves, suits, wipes, small hardware, molecular sieves e posed to } \\
\text { low level } \mathrm{H}_{3} \text {, solidified liquids }\end{array}$ \\
\hline $\begin{array}{l}\text { Liquid low level } \\
\text { radioactive }\end{array}$ & $2,000 \mathrm{gal} / \mathrm{y}$ & $2,000 \mathrm{gal} / \mathrm{y}$ & water based cleaners cxposed to low levels of $\mathrm{H}_{3}$ \\
\hline
\end{tabular}

